\title{
Daily activity and nest attendance in a breeding pair of Parrot Crossbills Loxia pytyopsittacus in southern Norway
}

\author{
Ronny Steen ${ }^{1 *}$, Anne-Marie Austad ${ }^{1}$, Johnny Steen ${ }^{2} \&$ Bjørn Aksel Bjerke ${ }^{3}$ \\ ${ }^{1}$ Faculty of Environmental Sciences and Natural Resource Management, Norwegian University of Life Sciences, NO-1432 Ås, \\ Norway \\ ${ }^{2}$ Parkveien 32, NO-1880 Eidsberg, Norway \\ ${ }^{3}$ Department of Zoology, Natural History Museum, University of Oslo, NO-0318 Oslo, Norway \\ ${ }^{*}$ Correspondence: ronny.steen@nmbu.no
}

\begin{abstract}
Crossbills Loxia spp. breed during late winter and early spring and feed their nestlings almost exclusively with seeds from conifer cones. In the present paper, we studied a breeding pair of Parrot Crossbills Loxia pytyopsittacus from dawn to dusk in Southern Norway using a time-lapse camera. The study was conducted in the second half of the nestling period, when the nestlings were from 10 to 21 days old and capable of keeping warm without assistance from the female. Almost all recorded parental nest visits involved feeding the nestlings. The average number of feeding visits was about 10 visits per day by each parent and these visits were distributed evenly throughout the day, starting about 30 min after sunrise and ending $60 \mathrm{~min}$ before sunset. Parents fed the young regularly at about 1-hour intervals. The female feeding duration was constant throughout the period, whereas the male feeding duration was longer initially, but decreased compared with the female later in the nestling period. In most feeding visits, the male and female arrived at the nest at the same time or shortly after to each other. The probability of parents removing nestlings' faecal sacs was very high during the early period, but decreased as the nestlings became older. Overall, our use of modern camera monitoring technology enabled a more comprehensive description of a pair of Parrot Crossbill's daily activity patterns and nest attendance behaviour than previous studies conducted by observations from a hide.
\end{abstract}

Key words: breeding, crossbill, feeding, food provisioning, nest attendance, parental effort

\section{INTRODUCTION}

During breeding, birds spend time laying and incubating eggs, feeding dependent nestlings, territory guarding, nest defense, nest cleaning, brooding and resting. In evolutionary terms, parents are assumed to maximise total food delivery to the brood, given the time constraints set by self-feeding and delivery (Ydenberg 2007). Therefore, the timing of breeding is adapted to when food is plentiful (Perrins 1970). At northern latitudes, the breeding season commences during spring with increasing temperature and food availability (Lack 1950). For many passerine birds, invertebrates become an important source of protein for dependent nestlings (e.g. Chamberlain et al. 1999, Wilkin et al. 2009). Even seed-eating birds, such as fringilline finches, select invertebrates for their young, which differs from their natural diets (Newton 1967). The cardueline finches, on the other hand, feed their young mainly on seeds (Newton 1967). Crossbills Loxia spp. belong to the finch family (Fringillidae) and the subfamily Carduelinae, and feed their nestlings almost exclusively with seeds. The breeding of crossbills is, therefore, independent of a supply of invertebrates, but dependent on the abundance of seeds (Newton 1967), with seeds from conifer cones being their main diet
(Cramp \& Perrins 1994).

In the present paper, we studied a breeding pair of Parrot Crossbill Loxia pytyopsittacus. The main breeding range is in the boreal forests of northwest Europe and into western Russia (Cramp \& Perrins 1994). In Norway, Parrot Crossbills are reported to breed as early as in February, although more commonly during March and April (Haftorn 1971). During egglaying, incubation and early nestling phases, the male provides most of the food either directly to the nestlings or via the female at the nest or a place close to the nest (Olsson 1960). The female broods the young until they are about 8-10 days old (Summers 2006). When relieved from the need to brood, the female also takes part in the food gathering (Olsson 1960, Summers 2006).

Traditionally, data on breeding behaviour has been obtained by on-site direct observations from a hide (Green 1976). Such observations are timeconsuming and often characterised by difficulties to maintain continuous surveillance of the nest. Further, human presence may disturb the birds. Recently, video monitoring technology has enabled detailed data on nest attendance (Steen 2009, Steen et al. 2011, Steen et al. 2012). For the Parrot Crossbill, there are only three detailed studies of nest attendance. The first two studies 

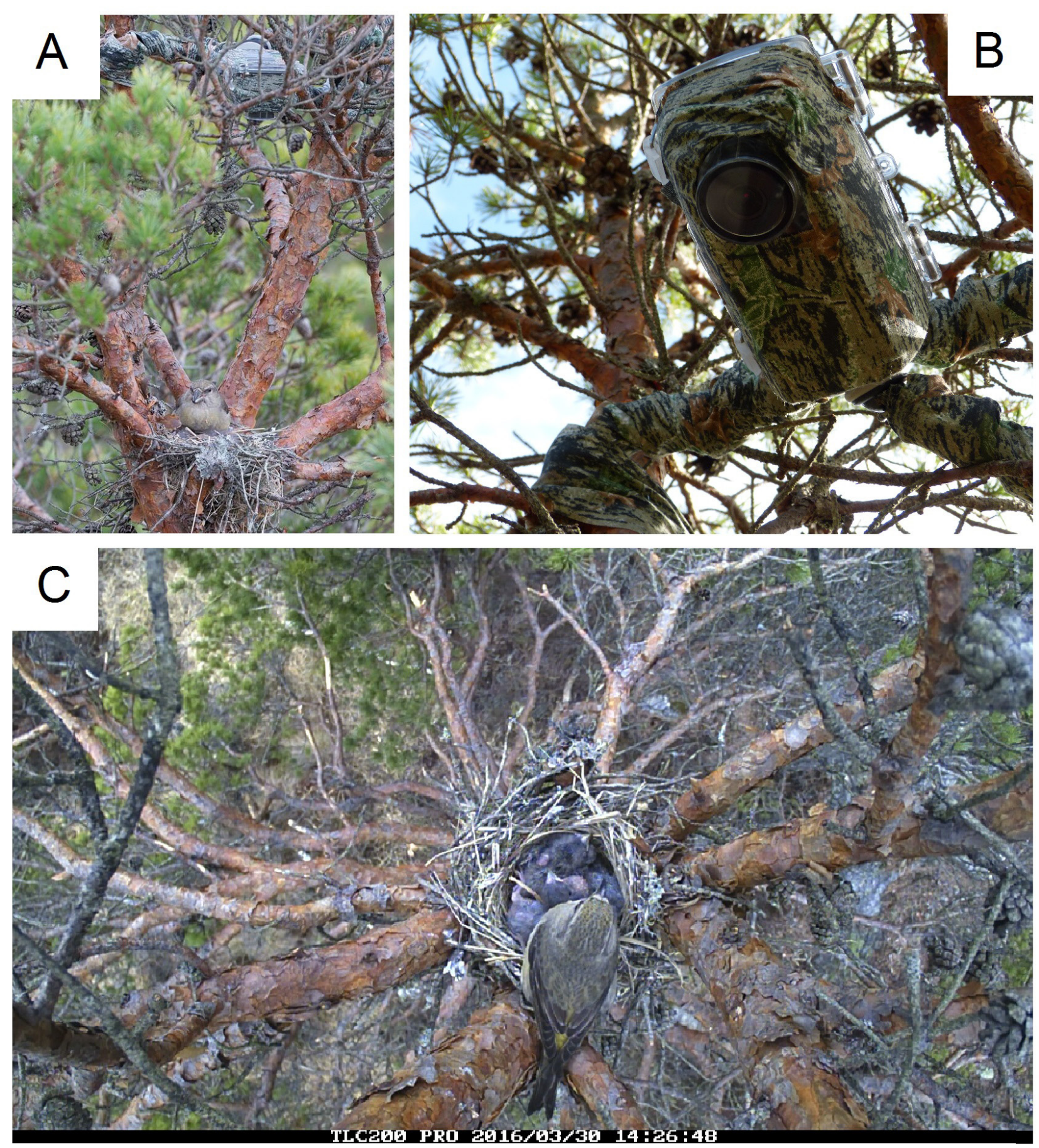

Figure 1. A) Photo of the nest with the nestlings covered by the female Parrot Crossbill and the time-lapse camera positioned above the nest, B) time-lapse camera positioned above the nest (30-40 cm), C) camera view (30 March 2016).

were performed by direct observation from a hide and provided anecdotal data without the use of statistical tests (Olsson 1960, Spjøtvoll 1972), and the second by the use of a video camera (Summers 2006). Olsson (1960) observed a breeding pair for about 50 hours to document nest building, incubation, brooding and food provisioning (brood size $=4$ ). Spjøtvoll (1972) sporadically observed a breeding pair throughout the incubation, brooding and food provisioning phases, although the hours of observation were not stated (brood size $=3$ ). Summers (2006) video-recorded one nest from the laying of the first egg to fledging, allowing a detailed description of nest attendance by the parents (brood size $=4$ ).

The present study consisted of video monitoring when the nestlings were 10 to 21 days old (148 hours of monitoring from dawn to dusk), which is when the nestlings are able to keep warm without assistance from the female. The aim of the study was to provide data on daily activity and nest attendance during the period 
when the female also takes part in the food gathering. We also investigated whether there was a division of labour between the sexes. The results were compared with the three studies mentioned above (Olsson 1960, Spjøtvoll 1972, Summers 2006).

\section{METHODS}

\section{Study area}

The study area was located in a boreal forest within Halden municipality in the county of Østfold $\left(59^{\circ} 11^{\prime} 20^{\prime \prime} \mathrm{N}, 11^{\circ} 24^{\prime} 30^{\prime \prime} \mathrm{E}\right)$. The nest was situated in a Scots pine Pinus sylvestris in the uppermost branches ( $4 \mathrm{~m}$ above ground). Conifer trees such as Scots pine and Norway spruce Picea abies dominate the forest. The study species, Parrot Crossbill, was distinguished from the Common Crossbill Loxia curvirostra by having larger head and bill (Haftorn 1971). The brood size was four nestlings and video monitoring was conducted when the nestlings were 10-21 days old (hatching date 20 March 2016, determined by inspecting the nest from a neighboring three some days until hatching). We obtained temperature $\left({ }^{\circ} \mathrm{C}\right)$ from the web portal (www.yr.no) and using the closest official weather station available (distance $\approx 20 \mathrm{~km}$ ). During our study, the average daily temperature was $5.6^{\circ} \mathrm{C}$ (range $=2.8-8.8$ ), and about $3{ }^{\circ} \mathrm{C}$ higher than normal temperature (Appendix 1)

\section{Camera monitoring}

We used a time-lapse camera, Brinno TLC200 PRO (Brinno Inc., Taiwan), mounted $30 \mathrm{~cm}$ above the nest (Figure 1). An example of video footage is available at https://vimeo.com/animalbehaviour/crossbill. The time-lapse camera was protected against severe weather by a weather-resistant housing (Brinno ATH120) and attached to the stem of the tree by a flexible tripod (Joby Gorillapod SLR-Zoom, Joby Inc., USA). Both the tripod and the camera housing were masked with camouflage tape. We used 4 x AA Energizer ${ }^{\circledR}$ Ultimate Lithium $^{\mathrm{TM}}$ batteries (Energizer Holdings, Inc., USA) to power the camera and the footage was stored onto SanDisk 32GB Class 4 SDHC Memory Cards (Sandisk Corp., USA). The time-lapse camera operated from 30 March to 10 April and was set to record between 0500 to $2100 \mathrm{~h}$ (about one hour before sunrise and one hour after sunset) to cover the whole daytime period. The camera was capable of providing sufficient images even during low light intensity, thereby allowing us to register if the female brooded at the onset and the conclusion of the night. Data for one monitoring day were missed due to lack of data storage space (see Appendix 2).
During the first days of monitoring, we used a time interval of 2 seconds (i.e. one image every third second); afterwards, the time interval was changed to 3 seconds to prolong the monitoring time on one memory card. From the captured images, the time-lapse camera automatically produced an AVI (Audio Video Interleaved) file with a selectable frame rate. We chose 1 frame per second (fps) to enable a proper inspection of each captured image. To review the footage, we used the program Brinno Video Player (1.107.0) that comes with the Brinno camera.

\section{Behavioural observations}

From the camera material, we registered every parental visit to the nest and classified the sex of the parent based upon their different coloured plumage (Figure 2). Further, we classified whether the parents brooded nestlings, fed the nestlings, or removed nestlings' faecal sacs. We measured the time spent at the nest and the feeding duration. As the nestlings were 10 days old at the initiation of the study, the female only brooded the nestlings the two first nights (indicated by the female brooding at the onset and conclusion of the nights); hence, we did not include brooding time in the analyses. All the visits to the nest were associated with feeding (except two nights with brooding and two incidences of the parents only removing nestlings' faecal sacs).

A feeding visit typically consisted of the parents arriving the nest at approximately same time (i.e. both were present at the nest during the visit) or shortly after each other $(<35 \mathrm{~s}$ between arrivals). Synchronised feeding like this was defined to belong to the same feeding bout. Similarly, when only one parent arrived at the nest, separated in time from the other, it was defined as a unique feeding bout. To investigate the time between feedings, we measured the time since the last feeding bout (i.e. time since conclusion of previous feeding). We excluded time differences for feeding bouts separated by the night, i.e. time between the first feeding bout for a given day and the last feeding bout the day before, which yielded a total of 88 feeding bouts used for the analyses.

We did not measure true feeding time due to the low precision with the current time-lapse settings (i.e. intervals of 3 seconds). A minimum would have been an interval of 1 second for precise timing and subtractions of short pauses (e.g. times used for vigilance during feeding). Therefore, we define feeding duration as the time elapsed between the initiation and conclusion of feeding dependent nestlings, subtracting for apparent breaks $(>5 \mathrm{~s})$.

\section{Statistics}

The statistical analyses were performed with the 


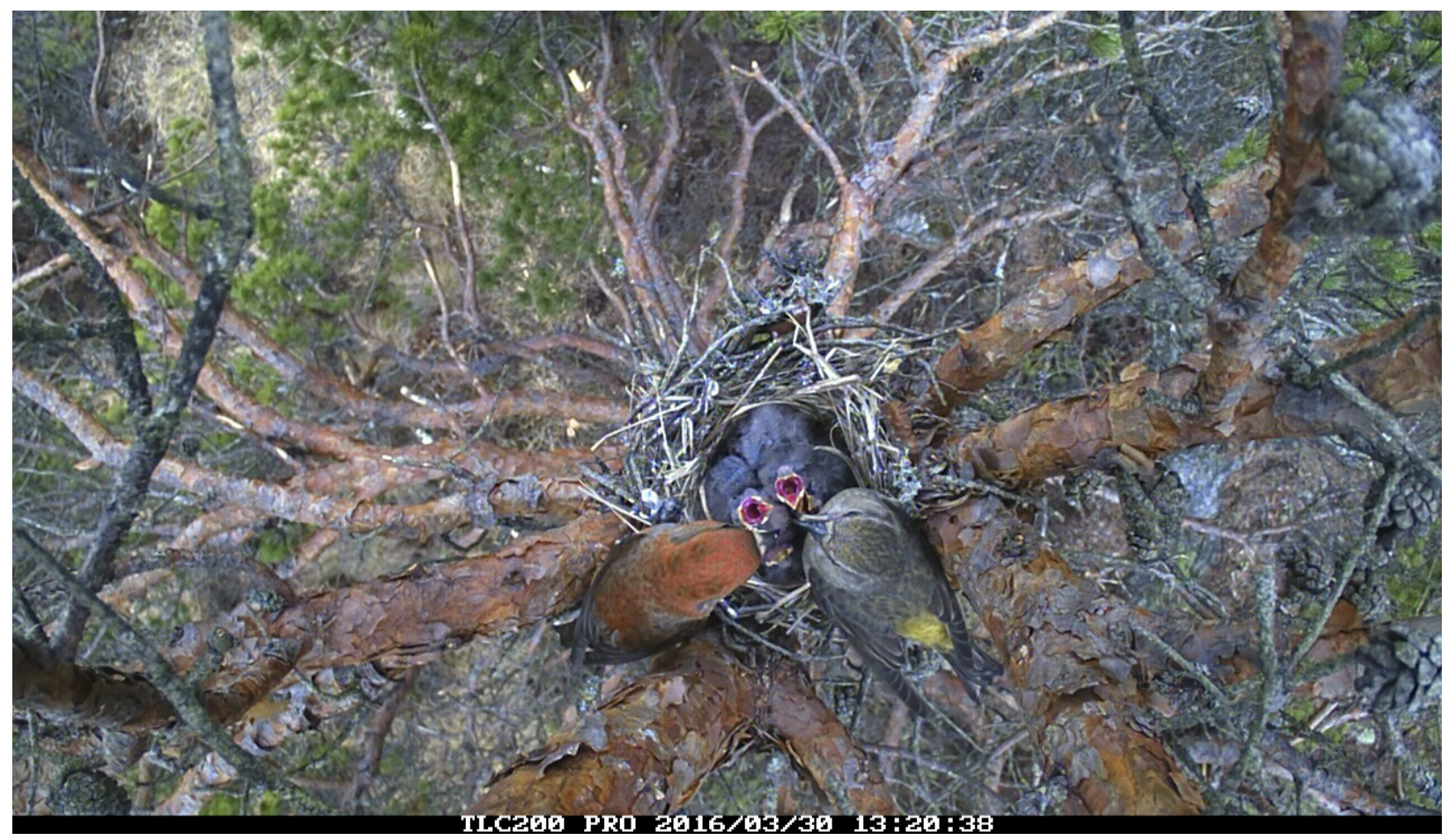

Figure 2. Image from time-lapse camera footage of Parrot Crossbill parents at the nest at the same time, both feeding the nestlings (the male to the left and female to the right, 30 March 2016).

program R (version 3.1.0) with the 'stats' package ( $\mathrm{R}$ Development Core Team 2016).

We used generalised linear models (glm) and binary logistic regression to test if the probability of the foodproviding sex (female vs male) changed as the nestlings became older (period: 10-21 days). Similarly, we tested if the probability of parents removing nestlings' faecal sacs changed as the nestlings became older and, in addition, if this was affected by whether the visitor was the female or the male (including the interaction term between 'sex of parent' and 'nestling age').

We used linear model $(\mathrm{lm})$ linear regression to test if the feeding duration differed between the male and the female as a function of nestling age (including the interaction term between 'sex of parent' and 'nestling age'). We used diagnostic plots to check if the residuals of the model were normally distributed. To achieve normal distribution we $\log _{10}$ transformed the dependent variable 'feeding duration'. We used the 'relevel' command to change the reference level of the factor 'sex of parent' (i.e. baseline was either male or female) to achieve parameter estimates for each sex.

\section{RESULTS}

During the monitoring period, a total of 188 unique feeding visits were registered. In addition, we observed two visits in which the parents only removed faecal sacs. The female brooded the nestlings during the two first nights (i.e. nestlings being 10-12 days old). These days had also a lower minimum temperature compared to the other days (Appendix 1).

Out of the 188 feeding visits, the male and female each provided food an equal number of times (94 feedings each). Most feeding visits by the parents were synchronised. Both parents were present together at the nest 57 times, with both parents providing food (Figure $2)$. In 32 feedings, one parent arrived shortly after the other and provided food to the nestlings $(<35 \mathrm{~s}$ since the conclusion of previous visit regardless of sex) though the female was observed to be the first to arrive in all cases except one. Separate visits were only observed 10 times: 8 visits separated by more than $60 \mathrm{~min}$, one with an interval of $\sim 6 \mathrm{~min}$ and one with $\sim 19 \mathrm{~min}$. Of these separate visits, the male and female each provided food an equal number of times ( 5 feedings each). There was no significant difference in the probability of the fooddelivering sex (male vs female) as the nestlings grew older $(\mathrm{RD}=260.6, \mathrm{df}=186, \mathrm{n}=188, \mathrm{p}=0.84$, Figure $3)$.

The feeding visits were distributed throughout the day, starting around sunrise and finishing about 1 hour before sunset (Figure 4). The highest feeding visit rate was registered at between 7 and $8 \mathrm{am}$. When both parents were present at the nest at the same time, the visit lasted, on average, $1 \mathrm{~min} 24 \mathrm{~s}( \pm 1 \mathrm{~min} 5 \mathrm{~s} \mathrm{SD}$., range: $16 \mathrm{~s}-8 \min 26 \mathrm{~s}, \mathrm{n}=57$ ). When only one parent arrived at the nest, the visit lasted, on average, $35 \mathrm{~s}$ ( $\pm 16 \mathrm{~s}$ SD, range: $8 \mathrm{~s}-1 \mathrm{~min} 42 \mathrm{~s}, \mathrm{n}=72$ ).

The average time between feeding bouts was 71 $\min ( \pm 20$ SD, range: $7-144 \min , n=88)$ (Figure 5). 


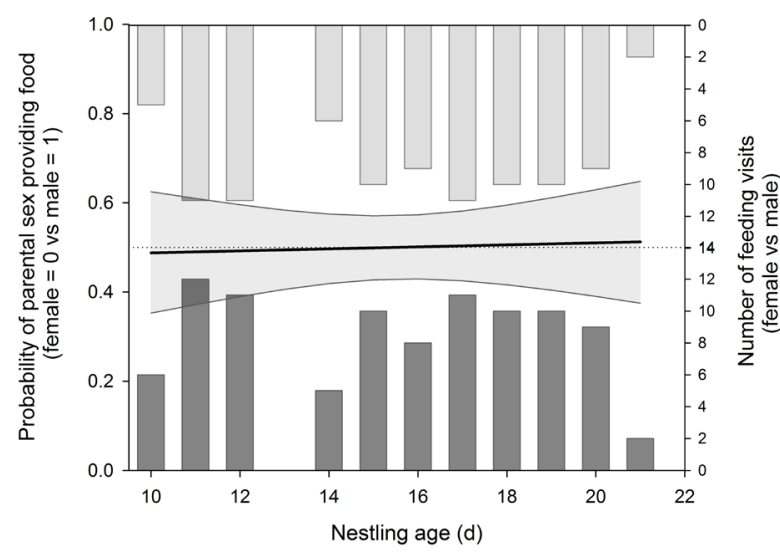

Figure 3. Logistic regression with the probability that the food-providing parent was the male or the female as a function of nestling age in the Parrot Crossbill). The left y-axis refers to the probability, the black line denotes the probability curve and the grey area shows the lower and upper confidence limits $(95 \%)$. The right $y$-axis refers to the raw data with the number of times food were provided; upper bars denote the number of times the male delivered food (grey bars) and lower bars denote the number of times the female delivered food (darkgrey bars). Note, for 'number of feeding visits' some days are affected by different monitoring effort, for details see Appendix 2.

The feeding duration differed between males and females as a function of nestling age (Table 1). For the female, the effect of nestling age was not significant. In contrast, for the male, the feeding duration decreased as the nestlings grew older (Figure 6).

The probability of parents removing nestlings' faecal sacs decreased significantly as the nestlings became older, although there was no difference between the female and the male parent (Table 2). The probability of removing nestlings' faecal sacs was high when the nestlings were 10-15 days old, and this decreased thereafter, with the lowest probability close to $50 \%$ when the nestlings were 21 days old (Figure 7 ).

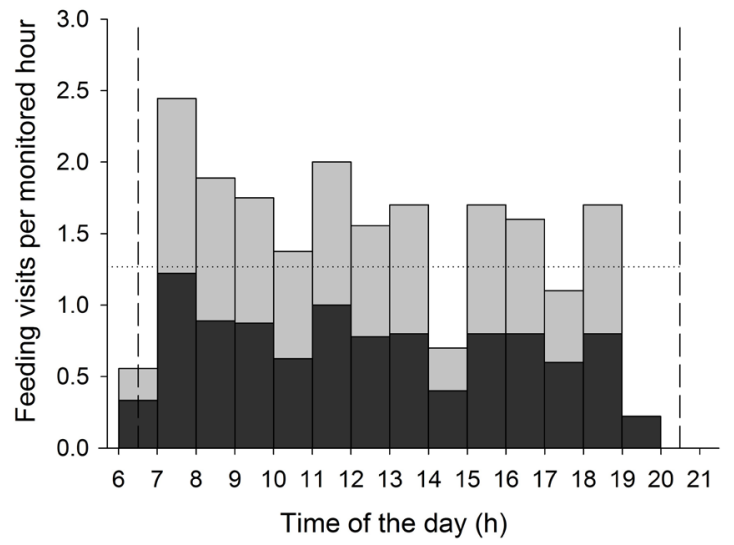

Figure 4. Feeding visits per monitored hour in relation to time of the day (divided into hourly blocks) in the Parrot Crossbill. Dark-grey bars denoting feeding visits by the female and light-grey bars by the male ( $\mathrm{n}=188,11$ days of monitoring). The dashed lines denote sunrise and sunset. The dotted line denotes the average.

\section{DISCUSSION}

During the monitored period, all visits during the day consisted of feeding the dependent nestlings, except for two visits in which the parents only removed faecal sacs. We did not observe any brooding during the day. Summers (2006) observed that in the first days after hatching, the female stayed constantly on the nest whilst the male brought food to the chicks and female. However, after a few days, the female accompanied the male during food gathering and brooded between foraging bouts. Brooding time decreased as the young got older and ceased completely when the nestlings were around nine days old (Summers 2006), which is in line with our observations. Only the first two nights in the monitoring period, when the young were between 10 and 12 days old, did the female brood them

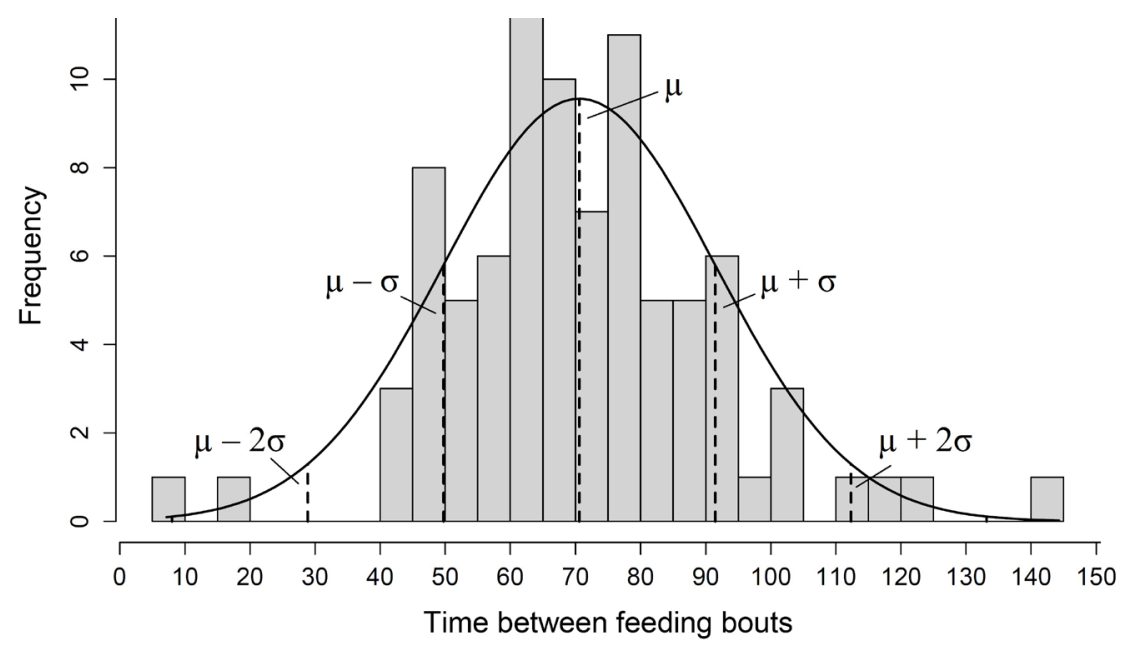

Figure 5. Frequency of time between feeding bouts in the Parrot Crossbill $(\mathrm{n}=88)$ divided into $5 \mathrm{~min}$ bins. The solid line is the normal curve with central dashed line representing the mean $(\mu)$, with \pm sd. $(\sigma)$ presented as dashed lines at left and right of $\mu$ $(\mu \pm \sigma$ and $\mu \pm 2 \sigma)$. Confidence interval $(95 \%)$ is the area between the outermost dashed lines $(\mu-2 \sigma$ and $\mu+2 \sigma$ ). 


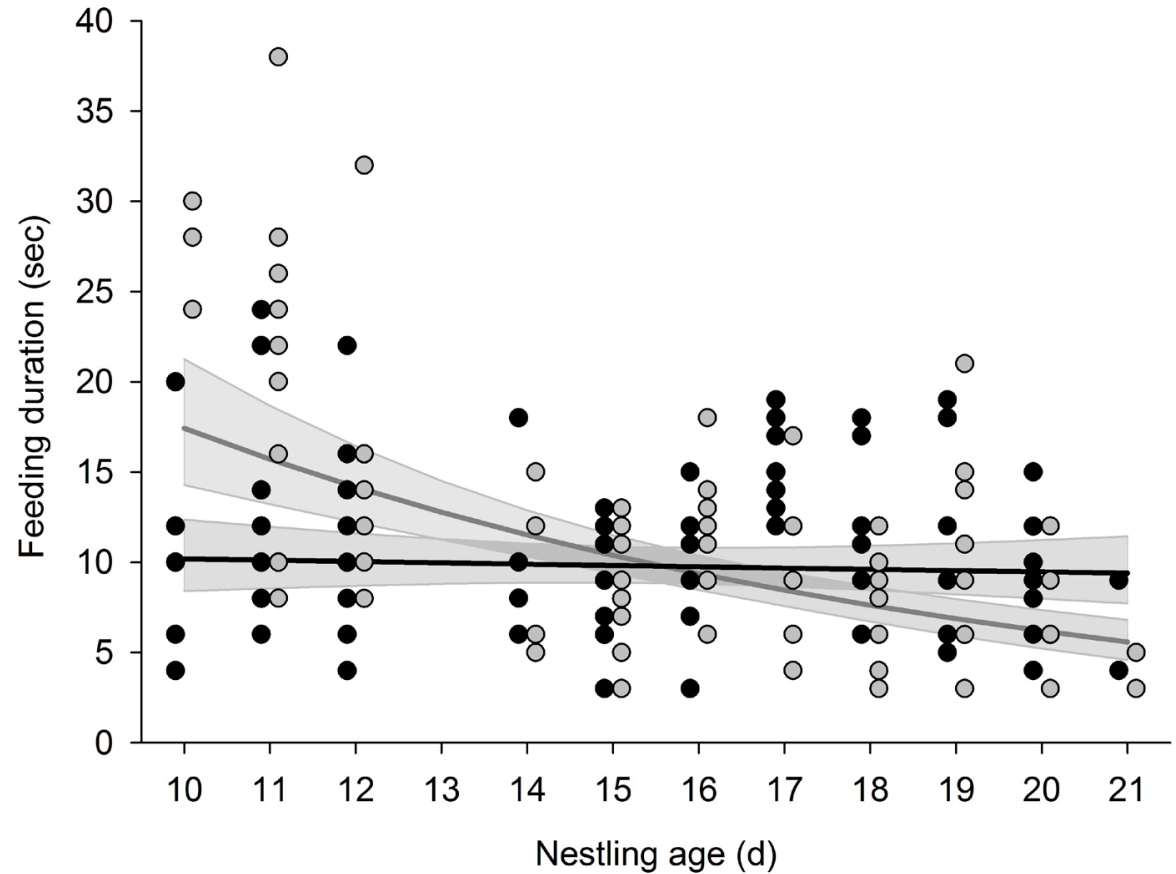

Figure 6. Feeding time (seconds) as function of nestling age in the Parrot Crossbill (back-transform by raising 10 to the power of fitted values, parameter estimates given in Table 1). Grey and black dots and lines denote male and female, respectively, with the grey shaded area showing the lower and upper confidence limits $(95 \%)$ for each curve. through the whole night, leaving the nest at $0619 \mathrm{~h}$ and 0626h, respectively, with sunrise at c. 0600h. Summers (2006) made similar observations and found nighttime brooding decreased when nestlings were 8-11 days old and brooding ceased when they were 11 days old.

The number of feeding visits was relatively constant throughout the observation period. The average number of visits per monitored hour was 0.63 for both sexes, which equals 10 visits per day by each parent and similar to what Summers (2006) found (12.6 visits per day for males and 11.1 for females). When only one parent arrived at the nest, the visit lasted, on average, $35 \mathrm{~s}$, whereas when both parents arrived simultaneously the visit lasted an average of 84 seconds. Summers (2006) did not distinguish between both parents and a single parent visiting the nest, but his numbers were close to ours, with visits lasting for $54 \mathrm{~s}$, on average.

Most feeding visits $(94.7 \%)$ were synchronised, where the male and female arrived at the nest at the same time or shortly after each other. During the brood-rearing period, Summers (2006) also observed that the parents often came to the nest together. Similarly, Spjøtvoll (1972) observed the parents almost exclusively arriving at the nest at the same time when nestlings were 16-17 days old. The fact that the parents arrived together at the nest indicates that they were gathering food together, or in some form of communication between them while foraging. Olsson (1960) proposed that the female could recognise the male's call and distinguish it from the calls of other crossbill individuals and vice versa. As proposed by Summers (2006), visits by parents might be synchronised to minimise advertising the nest to arboreal predators, such as red squirrels Sciurus vulgaris and pine martens Martes martes (Summers et al. 2002).

We found that parents fed the young more or less

Table 1. Parameter estimates from the multiple linear regression with feeding duration $\left(\log _{10}\right.$ seconds) as a function of nestling age and sex of the parent provisioning the food in Parrot Crossbill ( $\mathrm{df}=184$, freedom $\mathrm{R}_{\text {adj }}: 0.19$ squared, $\left.\mathrm{n}=188\right)$. A) Parental female as baseline and B) male as baseline (i.e. dummy variables).

\begin{tabular}{lcccc}
\hline \multicolumn{1}{c}{ Parameters } & Estimate & SE & $\mathrm{t}$ & $\mathrm{p}$ \\
\hline & & & & \\
A) Intercept & 1.04 & 0.11 & 9.874 & $<0.001$ \\
Age & -0.003 & 0.01 & -0.48 & 0.63 \\
Sex 'male' & 0.650 & 0.15 & 4.30 & $<0.001$ \\
Age*Sex 'male' & -0.042 & 0.01 & -4.36 & $<0.001$ \\
& & & & \\
B) & 1.69 & 0.101 & 15.585 & $<0.001$ \\
Agtercept & -0.045 & 0.01 & -6.57 & $<0.001$ \\
Sex 'female' & -0.650 & 0.15 & -4.3 & $<0.001$ \\
Age*Sex 'female' & 0.042 & 0.01 & 4.36 & $<0.001$ \\
\hline
\end{tabular}




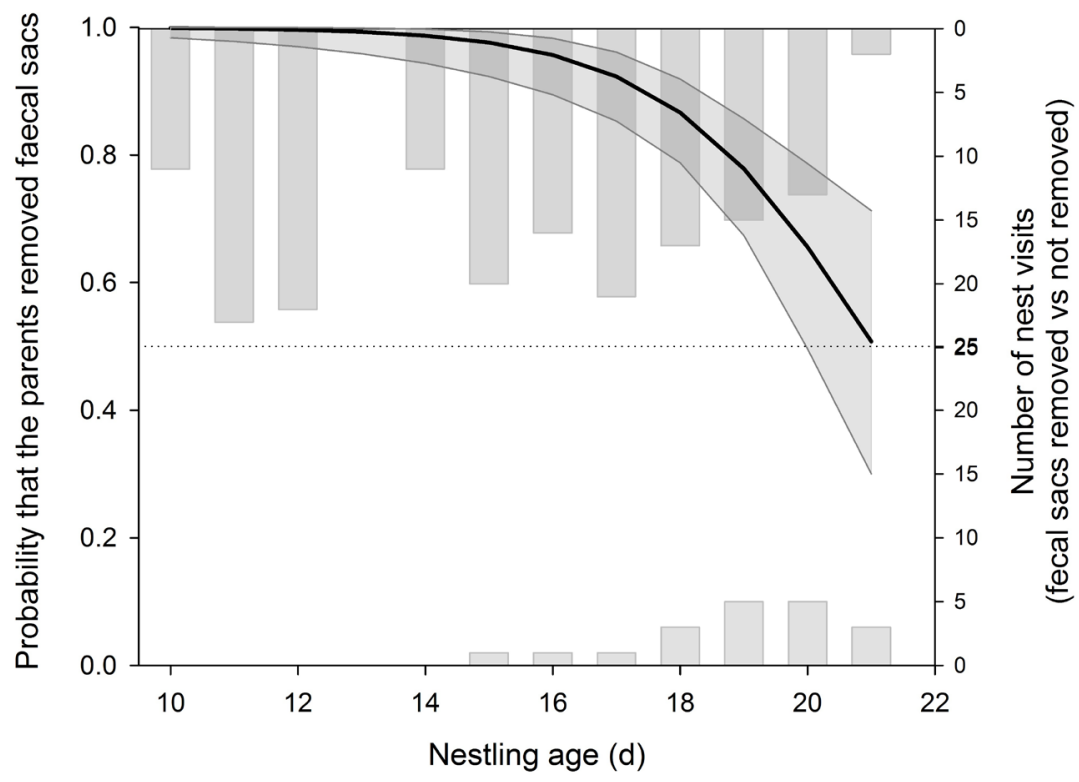

Figure 7. Probability that the parents removed their nestlings' faecal sacs from the nest as a function of nestling age in the Parrot Crossbill (logistic regression, parameter estimates given in Table 2). The left y-axis refers to the probability, the black line denotes the probability curve and the grey area shows the lower and upper confidence limits. The right y-axis refers to the raw data with the number of times a dropping was removed or not for each nestling age class, upper bars denote the times when droppings were removed and lower when they were not removed.

every hour (on average $70 \mathrm{~min}$, range $7-144 \mathrm{~min}$ ). This is in line with Olsson (1960) who found it to be, on average, $75 \mathrm{~min}$. Spjøtvoll (1972) found this period to range between 45-75 min and Summers (2006) found it to be, on average, $65 \mathrm{~min}$ (range 30-79 $\mathrm{min}$ ).

We found no significant difference between the sexes in feeding visits when nestlings were 10 days or older. However, there was a sex difference in feeding duration. The female feeding duration was constant throughout the period, whereas the males' feeding duration was higher in the early period (nestlings 10-13 days old), but decreased as the nestlings got older and was lower compared with females later in the period (nestlings 18-19 days old). We were not capable to judge portion size due to low frame rate and camera position, although we consider feeding duration to be correlated with food portion size (Bañbura et al. 1999). In fact, Spjøtvoll (1972) observed anecdotally that the male provided larger food portions compared with the female at early nestling stages (nestlings 7-8 days old) and that this relationship increased as time elapsed, with males providing smaller food portions than females during the late nestling stages. Summers (2006) did not directly state if the feeding duration by either sex decreased with time, but the male's feeding rate diminished during the brood-rearing period, with only one visit on the day the young fledged. A decrease

Table 2. Parameter estimates from the multiple logistic regression with the probability that the parents remove their nestlings' faecal sacs from the nest as a function of nestling age in Parrot Crossbill $(\mathrm{RD}=93.3, \mathrm{df}=188, \mathrm{n}=190)$.

\begin{tabular}{lcccc}
\hline Parameters & Estimate & SE & $\mathrm{z}$ & $\mathrm{p}$ \\
\hline (Intercept) & 12.894 & 2.89 & 4.47 & $<0.001$ \\
Age & -0.613 & 0.15 & -3.98 & $<0.001$ \\
\hline
\end{tabular}

in feeding rate is expected, at least during the last days of the monitoring period, as crossbill parents may use this as an encouragement for the young to fledge (Nethersole-Thompson 1975). However, we were not able to monitor the two last days before fledging due to limited data storage capability.

Both sexes removed faecal sacs throughout the monitoring period; however, the rate decreased significantly as the nestlings grew older. During the first half of the monitoring period there was a high probability of removing faecal sacs at every visit, but during the second half the likelihood was reduced and faecal sacs accumulated rapidly in and around the nest, particularly at the end of the monitoring period. Even so, until the nestlings were 20 days old there was a probability of more than $50 \%$ of removing faecal sacs. Compared with previous studies this was expected (Olsson 1960, Summers 2006), with both the male and female parent removing faecal sacs after feeding. However, as the chicks grew and more faeces were produced more faeces accumulated at the nest. With our placement of the camera and the low frame rate we cannot quantify if they just removed faeces or if they consumed the faecal sacs, although it appears from the footage that consumption occurred. In previous studies it has been documented that especially the female Parrot Crossbill consumed the faecal sacs during incubation and during the first days after hatching (Olsson 1960, Summers 2006). Olsson (1960) observed that in the beginning, the faecal sacs were consumed by the female and later also by the male, but the droppings were never carried away from the nest. Summers (2006) also observed that the adults regularly removed faecal sacs, with indication of both removing and consuming them.

Overall, our comprehensive camera monitoring of a breeding Parrot Crossbill pair using modern technology complemented data on the daily activity 
patterns and nest attendance found by other studies on single breeding pairs (Olsson 1960, Spjøtvoll 1972, Summers 2006). The data available for comparison are limited to two studies of direct observation and one of video observation and all at only one nest. The lack of data from the literature indicate the difficulties of documenting this species, particularly through direct observations from a hide. Our data, together with data from earlier studies, provide a better picture of the species' behaviour. For future studies, a similar camera system should observe several breeding pairs, although this is complicated by the difficulties in locating nests. Moreover, it would be important to cover several years' of observations to compare low and high years of cone production as this typically fluctuates over time (Pukkala et al. 2010).

Acknowledgements. We wish to thank Svein Dale for comments on the manuscript, and Candace G. Pettus for proof-reading and edits. Finally, we thank Tore Slagsvold and Ron Summers for comments of the submitted manuscript.

\section{REFERENCES}

Bañbura, J., Lambrechts, M. M., Blondel, J., Perret, P. \& Cartan-Son, M. 1999. Food handling time of Blue Tit chicks: constraints and adaptation to different prey types. Journal of Avian Biology 30: 263-270.

Chamberlain, D. E., Hatchwell, B. J. \& Perrins, C. M. 1999. Importance of feeding ecology to the reproductive success of Blackbirds Turdus merula nesting in rural habitats. Ibis 141: 415-427.

Cramp, S. \& Perrins, C. M. (eds.), 1994. The Birds of the Western Palearctic, Vol. VIII. Oxford University Press, Oxford.

Green, R. 1976. Breeding behaviour of Ospereys Pandion haliaetus in Scotland. Ibis 118: 475-490.

Haftorn, S. 1971 Norges fugler. Universitetsforlaget, Oslo.

Lack, D. 1950. The breeding seasons of European birds. Ibis 92: 288-316.

Nethersole-Thompson, D. 1975. Pine Crossbills. Poyser, Berkhamsted, UK.
Newton, I. 1967. The adaptive radiation and feeding ecology of some British finches. Ibis 109: 33-96.

Olsson, V. 1960. Iakttagelser vid ett bo av den större korsnäbben (Loxia pytyopsittacus). Vår Fågelvärld 19: $1-19$.

Perrins, C. M. 1970. The timing of birds' breeding season. Ibis 112: 242-255.

Pukkala, T., Hokkanen, T. \& Nikkanen, T. 2010. Prediction models for the annual seed crop of Norway spruce and Scots pine in Finland. Silva Fennica 44: 629-642.

R Development Core Team, 2016. R: A language and environment for statistical computing. $\mathrm{R}$ Foundation for Statistical Computing, Vienna, Austria. URL http:// www.R-project.org/.

Spjøtvoll, Ø. 1972. Litt om korsnebbens familieliv. Sterna 11: 201-213.

Steen, R. 2009. A portable digital video surveillance system to monitor prey deliveries at raptor nests. Journal of Raptor Research 43: 69-74.

Steen, R., Løw, L. M., Sonerud, G. A., Selås, V. \& Slagsvold, T. 2011. Prey delivery rates as estimates of prey consumption by Eurasian Kestrel Falco tinnunculus nestlings. Ardea 99: 1-8.

Steen, R., Sonerud, G. \& Slagsvold, T. 2012. Parents adjust feeding effort in relation to nestling age in the Eurasian Kestrel (Falco tinnunculus). Journal of Ornithology 153: 1087-1099.

Summers, R. W. 2006. Patterns of nest attendance by a pair of Parrot Crossbills. British Birds 99: 562-568.

Summers, R. W., Humphreys, E., Newell, M. \& Donald, C. 2002. Nest-site selection by crossbills Loxia spp. in ancient native pinewoods at Abernethy Forest, Strathspey, Highland. Bird Study 49: 258-262.

Wilkin, T. A., King, L. E. \& Sheldon, B. C. 2009. Habitat quality, nestling diet, and provisioning behaviour in Great Tits Parus major. Journal of Avian Biology 40: 135-145.

Ydenberg, R., 2007. Provisioning. Pp. 273-304 in: Stephens, D., Brown, J. \& Ydenberg, R. (eds.) Foraging behavior and ecology: University of Chicago Press, Chicago.

Received 21 December 2016. Accepted 19 April 2017 
Appendix 1. Daily temperature during the study. With minimum, maximum, average and normal temperatures in ${ }^{\circ} \mathrm{C}$.

\begin{tabular}{cccccc}
\hline $\begin{array}{c}\text { Nestling age } \\
\text { (days) }\end{array}$ & Date & Maximum & Minimum & Mean & Normal \\
\hline 10 & 30 Mar 2016 & $7.1^{\circ}$ & $2.4^{\circ}$ & $4.2^{\circ}$ & $1.9^{\circ}$ \\
11 & 31 Mar 2016 & $7.7^{\circ}$ & $-2.1^{\circ}$ & $2.8^{\circ}$ & $2.1^{\circ}$ \\
12 & 01 Apr 2016 & $7.9^{\circ}$ & $-0.5^{\circ}$ & $3.9^{\circ}$ & $2.2^{\circ}$ \\
13 & 02 Apr 2016 & $7.1^{\circ}$ & $4.1^{\circ}$ & $5.5^{\circ}$ & $2.3^{\circ}$ \\
14 & 03 Apr 2016 & $9.6^{\circ}$ & $4.9^{\circ}$ & $6.6^{\circ}$ & $2.5^{\circ}$ \\
15 & 04 Apr 2016 & $12.0^{\circ}$ & $5.7^{\circ}$ & $8.8^{\circ}$ & $2.6^{\circ}$ \\
16 & 05 Apr 2016 & $10.8^{\circ}$ & $5.8^{\circ}$ & $6.5^{\circ}$ & $2.7^{\circ}$ \\
17 & 06 Apr 2016 & $8.7^{\circ}$ & $5.2^{\circ}$ & $6.2^{\circ}$ & $2.9^{\circ}$ \\
18 & 07 Apr 2016 & $8.3^{\circ}$ & $5.2^{\circ}$ & $6.3^{\circ}$ & $3.0^{\circ}$ \\
19 & 08 Apr 2016 & $7.8^{\circ}$ & $4.0^{\circ}$ & $5.1^{\circ}$ & $3.1^{\circ}$ \\
20 & 09 Apr 2016 & $9.3^{\circ}$ & $2.4^{\circ}$ & $5.3^{\circ}$ & $3.3^{\circ}$ \\
21 & 10 Apr 2016 & $12.6^{\circ}$ & $1.4^{\circ}$ & $6.4^{\circ}$ & $3.4^{\circ}$ \\
\hline
\end{tabular}

Appendix 2. Hour-blocks monitored, which represent the intensity of monitoring. The small gap is due to a full SD card that could not store data for this period.

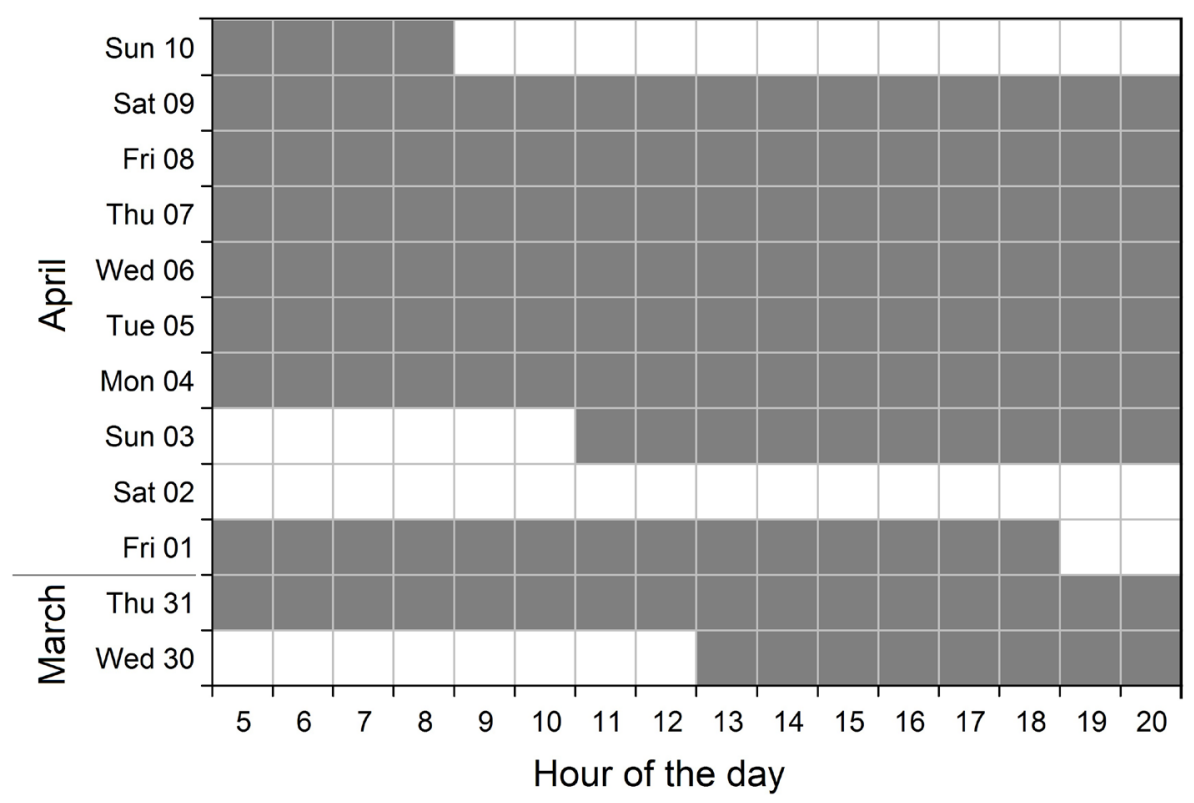

